\section{References}

1. Arber DA, Orazi A, Hasserjian R, et al. The 2016 revision to the World Health Organization classification of myeloid neoplasms and acute leukemia. Blood. 2016;127(20):2391-405.

2. Den Boer ML, van Slegtenhorst M, De Menezes RX, et al. A subtype of childhood acute lymphoblastic leukaemia with poor treatment outcome: a genome-wide classification study. Lancet Oncol. 2009;10(2):125-34

3. Mullighan CG, Su X, Zhang J, et al. Deletion of IKZF1 and prognosis in acute lymphoblastic leukemia. N Engl J Med. 2009;360(5):470-80.

4. Roberts KG, Gu Z, Payne-Turner D, et al. High frequency and poor outcome of Philadelphia chromosome-like acute lymphoblastic leukemia in adults. J Clin Oncol. 2017;35(4):394-401.

5. Tasian SK, Loh ML, Hunger SP. Philadelphia chromosome-like acute lymphoblastic leukemia. Blood. 2017;130(19):2064-2072.

6. Boer JM, Marchante JR, Evans WE, et al. BCR-ABL1-like cases in pediatric acute lymphoblastic leukemia: a comparison between DCOG/Erasmus MC and COG/St. Jude signatures. Haematologica. 2015;100(9): e354-7

7. Chiaretti S, Messina M, Della Starza I, et al. BCR-ABL1-like is associated with MRD persistence and poor outcome. First report of the MRD-oriented GIMEMA 1913. Haematologica 2020. doi: 10.3324/haematol.2020.247973

8. Chiaretti S, Messina M, Grammatico S, et al. Rapid identification of BCR/ABL1-like acute lymphoblastic leukaemia patients using a predictive statistical model based on quantitative real time-polymerase chain reaction: clinical, prognostic and therapeutic implications. $\mathrm{Br} \mathrm{J}$ Haematol. 2018;181(5):642-652.

9. Jain N, Roberts KG, Jabbour E, et al. Ph-like acute lymphoblastic leukemia: a high-risk subtype in adults. Blood. 2017;129(5):572-581.

10. Stock W, Luger SM, Advani AS, et al. A pediatric regimen for older adolescents and young adults with acute lymphoblastic leukemia: results of CALGB 10403. Blood. 2019;133(14):1548-1559.
11. Herold T, Schneider S, Metzeler KH, et al. Adults with Philadelphia chromosome-like acute lymphoblastic leukemia frequently have IGH-CRLF2 and JAK2 mutations, persistence of minimal residual disease and poor prognosis. Haematologica. 2017;102(1):130-138.

12. Tanasi I, Ba I, Sirvent N, et al. Efficacy of tyrosine kinase inhibitors in $\mathrm{Ph}$-like acute lymphoblastic leukemia harboring ABL-class rearrangements. Blood. 2019;134(16):1351-1355.

13. Pui CH, Roberts KG, Yang JJ, Mullighan CG. Philadelphia chromosome-like acute lymphoblastic leukemia. Clin Lymphoma Myeloma Leuk. 2017;17(8):464-470.

14. Foà R, Bassan R, Vitale A, et al. Dasatinib-Blinatumomab for PhPositive Acute Lymphoblastic Leukemia in Adults. N Engl J Med. 2020;383(17):1613-1623.

15. Harvey RC, Tasian SK. Clinical diagnostics, and treatment strategies for Philadelphia chromosome-like acute lymphoblastic leukemia. Blood Adv. 2020;4(1):218-228.

16. Cario G, Leoni V, Conter V, Baruchel A, Schrappe M, Biondi A. BCRABL1-like acute lymphoblastic leukemia in childhood and targeted therapy. Haematologica. 2020;105(9):207019.

17. Brown LM, Lonsdale A, Zhu A, et al. The application of RNA sequencing for the diagnosis and genomic classification of pediatric acute lymphoblastic leukemia. Blood Adv. 2020;4(5):930-942.

18. Anagnostou T, Knudson RA, Pearce KE, et al. Clinical utility of fluorescence in situ hybridization-based diagnosis of BCR-ABL1 like (Philadelphia chromosome like) B-acute lymphoblastic leukemia. Am J Hematol. 2020;95(3):e68-E72.

19. Sánchez R, Ribera J, Morgades M, et al. A novel targeted RNA-Seq panel identifies a subset of adult patients with acute lymphoblastic leukemia with BCR-ABL1-like characteristics. Blood Cancer J. 2020:10(4):43 doi: 10.1038/s41408-020-0308-3.

20. El Fakih R, Savani B, Mohty M, Aljurf M. Hematopoietic cell transplant consideration for Philadelphia chromosome-like acute lymphoblastic leukemia patients. Biol Blood Marrow Transplant. 2020;26(1):e16-e20.

\title{
Granulocyte colony-stimulating factor acts on lymphoid-biased, short-term hematopoietic stem cells
}

\section{Yulin Chen and K. Lenhard Rudolph} Leibniz Institute on Aging - Fritz Lipmann Institute (FLI), Research Group on Stem Cell Aging, Jena and Medical Faculty, University
Hospital Jena (UKJ), Jena, Germany

E-mail: K. LENHARD RUDOLPH - lenhard.rudolph@leibniz-fli.de

doi:10.3324/haematol.2020.271205

G ranulocyte colony-stimulating factor (G-CSF) is a cytokine that increases myelopoiesis, ${ }^{1}$ impairs lymphopoiesis by inhibiting committed progenitor cells, ${ }^{2,3}$ and enhances hematopoietic stem cell (HSC) mobilization. ${ }^{4}$ The direct effects of G-CSF on purified subpopulation of HSC remained to be delineated. In this issue of Haematologica, Xie et al. ${ }^{5}$ investigate the influence of G-CSF on proliferation and the repopulating potential of myeloidbiased, long-term $\mathrm{HSC}\left(\mathrm{CD} 201^{+} \mathrm{CD} 150^{+} \mathrm{CD} 48^{-} \mathrm{CD} 41^{-}\right.$ CD34-KSL) and lymphoid-biased, short-term HSC (CD201+CD150-CD48-CD41-CD34-KSL).

Understanding the direct influences of G-CSF on HSC could improve our understanding of HSC responses to an increase in G-CSF level caused by inflammation. ${ }^{6}$ The study by Xie et al. shows that G-CSF acts directly on lymphoid-biased, short-term HSC but not on myeloid-biased HSC. Interestingly, G-CSF cooperates with stem cell factor in driving the expansion of lymphoid-biased, shortterm HSC in culture and in maintaining the in vivo repopulating potential of such cultures. These findings suggest that G-CSF-mediated effects on lymphoid-biased, shortterm HSC may contribute to the previously noted enhancement of early lymphopoiesis of bone marrow stem and progenitor cells after exposure to G-CSF.? In contrast, however, G-CSF is also known to instruct bone marrow stromal cells to suppress the function of committed progenitors of B-lymphopoiesis. ${ }^{2}$ The functional relevance of the G-CSF-mediated priming of early lymphoid progenitor cells and lymphoid-biased $\mathrm{HSC}^{5,7}$ in association with G-CSF-mediated impairment in the progression of lymphopoiesis from committed progenitor cells ${ }^{2}$ should be delineated in future studies.

The primary role of G-CSF is currently seen in activation of myelopoiesis to strengthen myeloid immune responses, such as the recruitment of neutrophils during bacterial lung infections. ${ }^{8}$ However, the simultaneous priming of early lymphoid progenitor cells and lymphoidbiased HSC by G-CSF may also be important to ensure prompt reactivation of lymphopoiesis after the initial induction of myeloid cell-driven immune responses. The sequential coordination of such immune actions by GCSF seems to be an interesting area of future research.

Understanding direct influences of G-CSF on HSC could also be relevant for our understanding of HSC 


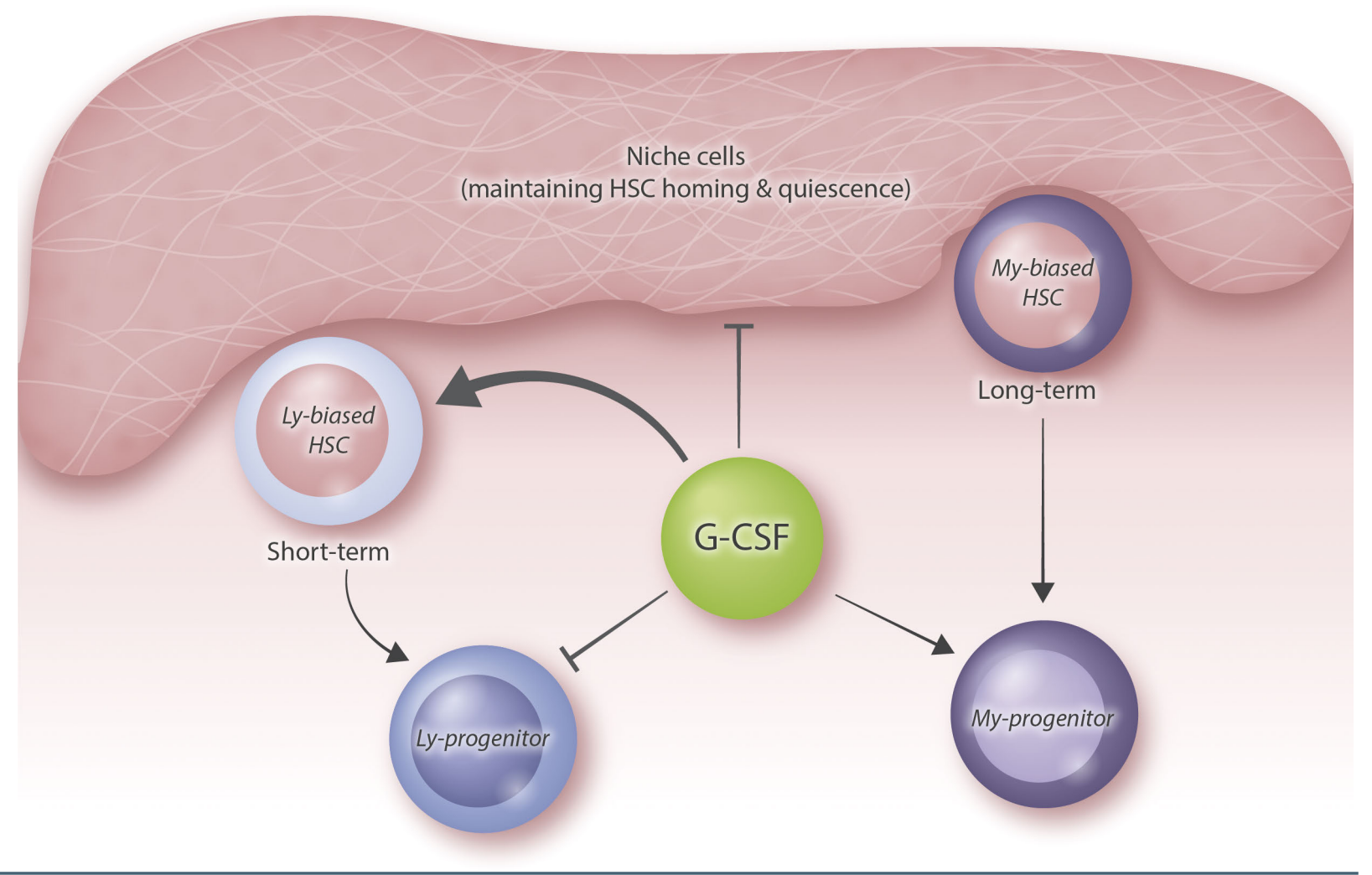

Figure 1. Granulocyte colony-stimulating factor influences the balance of myelopoiesis and lymphopoiesis. Granulocyte colony-stimulating factor (G-CSF) leads to mobilization of hematopoietic stem cells (HSC) by disrupting the function and maintenance of specific niche cells. G-CSF enhances expansion of lymphoid (Ly)-biased, shortterm HSC in culture and maintains their in vivo repopulating potential. In contrast, G-CSF does not have a direct effect on purified myeloid (My)-biased, long-term HSC. Apart from regulating HSC, G-CSF can also increase myelopoiesis and impair lymphopoiesis by regulating committed progenitor cells.

aging. During mouse aging, the number of myeloidbiased HSC increases more than 10-fold, whereas the number of lymphoid-biased HSC shows only a mild (2fold) increase. ${ }^{9,10}$ Xie et al. revealed that G-CSF improves the maintenance of lymphoid-biased HSC in culture, but does not have direct effects on myeloid-biased HSC. Whether G-CSF could contribute to the in vivo maintenance of lymphoid-biased HSC remains to be seen. Interestingly, in humans, G-CSF levels in the serum were reported to decrease during aging and this decrease was pronounced in patients with Alzheimer disease. ${ }^{11}$ The findings of Xie et al. suggest that aging-associated declines in G-CSF level could contribute to the relative reduction in the self-renewal of lymphoid-biased HSC versus myeloid-biased HSC during aging. It would be interesting to investigate whether G-CSF has similar effects on human lymphoid-biased HSC as those on murine HSC described by Xie et al. However, the discrimination between different subtypes of HSC (lymphoid vs. myeloid-biased) has not yet been established in humans.

In addition, it would be of great interest to analyze the influence of other aging-related factors on G-CSF levels and HSC aging. Telomere dysfunction occurs as a consequence of telomere shortening and represents one of the hallmarks of aging. Telomere shortening induces cellular senescence and a strong increase in the secretion of proinflammatory cytokines by senescent cells - referred to as the senescence-associated secretory phenotype (SASP). ${ }^{12}$ Of note, senescent cells also show strong increases in the secretion of G-CSF. ${ }^{13}$ An accumulation of senescent cells have been described to occur in various tissues of primates, including humans, during aging. ${ }^{14-16}$ Interestingly, genetic studies on telomerase knockout mice revealed that G-CSF increases in blood serum as a consequence of telomere dysfunction, which led to impairments in lymphopoiesis and myeloid-skewed hematopoiesis. ${ }^{17}$ This phenotype is very similar to that present in aging humans, which is also characterized by increases in myeloid relative to lymphoid cells in the blood. ${ }^{18}$ While studies on human serum showed decreases in G-CSF during aging, future studies should investigate whether the accumulation of senescent cells in bone marrow tissue may lead to increases in G-CSF levels in the micro-milieu of HSC and lymphoid progenitor cells. If G-CSF does indeed contribute to the reduction in lymphopoiesis during aging, this could be related to the inhibitory effect of G-CSF on committed lymphoid progenitor cells. ${ }^{2}$

A direct influence of G-CSF on HSC could also be relevant for the clinical usage of G-CSF. It has been shown that macrophage colony-stimulating factor acts directly on HSC to enhance myeloid differentiation, which has positive effects in protecting HSC-transplanted mice from Aspergillus infection. ${ }^{19}$ Two of the main applications of G-CSF are to ameliorate chemotherapy-induced neutropenia and to mobilize HSC to be used for mobilized peripheral blood (MPB) transplantation. G-CSF leads to the mobilization of HSC by disrupting the function and maintenance of specific niche cells. ${ }^{20}$ It remains to be determined whether direct effects of G-CSF on lymphoid-biased HSC would influence the mobilization of 
sub-populations of HSC. If so, the method of mobilization could have an impact on transplantation results. In breast cancer patients who need a transplant of autologous $\mathrm{MPB}$ as part of their anticancer therapy, the transplantation of purified HSC improved the survival outcomes compared to those receiving non-purified MPB (https://doi.org/10.1016/j.bbmt.2011.07.009). It remains to be seen whether direct effects of G-CSF on HSC may influence transplantation outcomes.

In brief, the study by XIe et al. provides very interesting new data indicating that G-CSF can act directly on lymphoid-biased but not on myeloid biased HSC. This finding may have implications for our understanding of immune responses, HSC aging, and bone marrow transplantation therapies.

\section{Disclosures}

No conflicts of interest to disclose.

\section{Contributions}

$Y C$ and KLR wrote the editorial together.

\section{Acknowledgments}

This work was funded by the German Research Foundation (DFG) within the CRC "PolyTarget" (SFB 1278, Project B01) and by the Federal Ministry of Research and Education (BMBF) within the HaematoOPT project (031A424D).

\section{References}

1. Liongue C, Hall CJ, O'Connell BA, Crosier P, Ward AC. Zebrafish granulocyte colony-stimulating factor receptor signaling promotes myelopoiesis and myeloid cell migration. Blood. 2009;113(11):25352546.

2. Day RB, Bhattacharya D, Nagasawa T, Link DC. Granulocyte colony-stimulating factor reprograms bone marrow stromal cells to actively suppress B lymphopoiesis in mice. Blood. 2015;125(20):3114-3117.

3. Ingrid GW, Bendall LJ, Forristal CE, et al. B-lymphopoiesis is stopped by mobilizing doses of G-CSF and is rescued by overexpression of the anti-apoptotic protein Bcl2. Haematologica. 2013;98(3):325-333.

4. Petit I, Szyper-Kravitz M,Nagler A, et al. G-CSF induces stem cell mobilization by decreasing bone marrow SDF-1 and up-regulating CXCR4. Nat Immunol. 2002;3(7):687-694.

5. Xie M, Zhang S, Dong F, et al. Granulocyte colony-stimulating factor directly acts on mouse lymphoid-biased but not myeloid-biased hematopoietic stem cells. Haematologica. 2021;106(6):1647-1658

6. Kawakami M, Tsutsumi H, Kumakawa T, et al. Levels of serum granulocyte colony-stimulating factor in patients with infections. Blood. 1990;76(10):1962-1964

7. Hirayama F, Shih JP, Awgulewitsch A, Warr GW, Clark SC, Ogawa M. Clonal proliferation of murine lymphohemopoietic progenitors in culture. Proc Natl Acad Sci U S A. 1992;89(13):5907-5911.

8. Ye P, Rodriguez FH, Kanaly S, et al. Requirement of interleukin 17 receptor signaling for lung Cxc chemokine and granulocyte colonystimulating factor expression, neutrophil recruitment, and host defense. J Exp Med. 2001;194(4):519-528.

9. Muller-Sieburg C, Sieburg HB. Stem cell aging: survival of the laziest? Cell Cycle. 2008;7(24):3798-3804.

10. Wang J, Morita Y, Han B, Niemann S, Löffler B, Rudolph KL. Per2 induction limits lymphoid-biased haematopoietic stem cells and lymphopoiesis in the context of DNA damage and ageing. Nat Cell Biol. 2016;18(5):480-490.

11. Laske C, Stellos K, Stransky E, Leyhe T, Gawaz M. Decreased plasma levels of granulocyte-colony stimulating factor (G-CSF) in patients with early Alzheimer's disease. J Alzheimers Dis. 2009; 17(1):115-123.

12. Salminen A, Kauppinen A, Kaarniranta K. Emerging role of NF- $\kappa B$ signaling in the induction of senescence-associated secretory phenotype (SASP). Cell Signal. 2012;24(4):835-845.

13. Xu M, Tchkonia T, Ding H, et al. JAK inhibition alleviates the cellular senescence-associated secretory phenotype and frailty in old age. Proc Natl Acad Sci U S A. 2015;112(46):E6301-6310.

14. Herbig U, Ferreira M, Condel L, Carey D, Sedivy JM. Cellular senescence in aging primates. Science. 2006;311(5765):1257.

15. Idda ML, McClusky WG, Dodde V, et al. Survey of senescent cell markers with age in human tissues. Aging (Albany NY) 2020;12(5):4052-4066.

16. Dimri GP, Lee X, Basile G, et al. A biomarker that identifies senescent human cells in culture and in aging skin in vivo. Proc Natl Acad Sci U S A. 1995;92(20):9363-9367.

17. Ju Z, Jiang H, Jaworski M, et al. Telomere dysfunction induces environmental alterations limiting hematopoietic stem cell function and engraftment. Nat Med. 2007;13(6):742-747.

18. Pang WW, Price EA, Sahoo D, et al. Human bone marrow hematopoietic stem cells are increased in frequency and myeloid-biased with age. Proc Natl Acad Sci U S A. 2011;108(50):20012-20017.

19. Kandalla PK, Sarrazin S, Molawi K, et al. M-CSF improves protection against bacterial and fungal infections after hematopoietic stem/progenitor cell transplantation. J Exp Med. 2016;213(11):22692279 .

20. Winkler IG, Sims NA, Pettit AR, et al. Bone marrow macrophages maintain hematopoietic stem cell (HSC) niches and their depletion mobilizes HSCs. Blood. 2010;116(23):4815-4828. 